\title{
Artigos
}

Viviane Drumond

\section{Formação de Professoras e Professores de Educação Infantil: Por uma Pedagogia da Infância}

\begin{abstract}
Resumo: Este artigo discute a formação de professores(as) de Educação Infantil nos cursos de pedagogia e destaca a docência com crianças pequenas como um campo de conhecimento em construção, isso implica em assumir compromissos com uma pedagogia centrada na criança e na experiência infantil. Desse modo, compreende os estágios como espaço privilegiado da formação, pois favorece a pesquisa, a reflexão e a inovação pedagógica. Além disso, propõe a arte como um dos fundamentos epistemológicos da pedagogia. $O$ estudo observou a importância de o curso de Pedagogia rever seu projeto pedagógico curricular, de modo a construir percursos formativos para professores(as) de creche, pré-escola e anos iniciais do Ensino Fundamental. Um curso de formação de professores(as) de crianças; uma Pedagogia da Infância.
\end{abstract}

Palavras-chave: Docência. Crianças. Estágio. Arte.

\section{Basic Teacher Training in Child Education: for a Pedagogy of Childhood}

Abstract: This paper discusses the basic training of teachers of both genders in Child Education in the undergraduate courses of Pedagogy. It highlights teaching work with small children as a field of knowledge under construction, which leads us to take commitment with a pedagogy focusing on children and their experiences. I see teacher internship as a privileged place for training, as it allows research, reflection, and pedagogical innovation. I also propose art as one of the epistemological pillars of pedagogy. My study showed the importance of the undergraduate course of Pedagogy in reviewing its pedagogical curricular project in order to define educative itineraries for teachers in daycare centers, preschool and the early grades of primary and middle school. A basic training for teachers that will work with children; a Pedagogy of Childhood.

Keywords: Teacher. Children. Internship. Art.

'Doutora em Educação pela Faculdade de Educação da Universidade Estadual de Campinas (UNICAMP). Professora do curso de Pedagogia da Universidade Federal de Tocantins (UFT). Atua nas seguintes áreas: Educação Infantil, formação de professores e estágio docente. E-mail: drumondviviane@gmail.com 
m 1996, com a Lei de Diretrizes e Bases da Educação (LDB), vamos encontrar a formulação da Educação Infantil como primeira etapa da Educação Básica. Desde então estamos procurando construir um modo de formar professores(as) e de compreender a docência na Educação Infantil. Ou seja, um modelo que não reproduz o trabalho docente dos demais níveis de ensino, mas que respeite as crianças, os processos educativos que exigem atenção às especificidades de cada faixa etária e as propostas centradas no binômio educar e cuidar.

A inclusão da Educação Infantil nos sistemas educacionais, especialmente a creche, colocou a necessidade de mudanças na formação de futuros(as) professores(as): adequação da estrutura física, dos materiais pedagógicos e das propostas de trabalho com as crianças. São questões que não estão sendo tratadas com a seriedade que merecem. Discutir a organização de uma política nacional e de formação de professores(as) para a Educação Infantil implica em assumir compromissos com a especificidade da educação da criança pequena.

O esfacelamento e a fragmentação da Educação Infantil, que vêm ocorrendo nos últimos anos - com as crianças de 6 anos no Ensino Fundamental e a obrigatoriedade da matrícula aos 4 anos - representam um retrocesso, pois estamos correndo sérios riscos de ter uma pré-escola preparatória, com os olhos voltados para o Ensino Fundamental, excluindo as crianças de 0 a 3 anos. A primeira etapa da Educação Básica, construída com a utopia de não antecipar a escola, de não ser preparatória, como um direito da criança e da família, corre o risco de sucumbir.

Entre as lutas pelos direitos das crianças pequenas e de suas famílias à Educação Infantil mostra-se extremamenteimportante discutir a formação de professores(as) de crianças, bem como os saberes e conhecimentos que vêm sendo discutidos nos cursos de formação inicial e continuada. Afinal, o que sabemos sobre as linguagens e as formas de comunicação entre os bebês? Como as crianças pequenas constroem saberes entre elas? Qual trabalho pedagógico vamos desenvolver com as crianças que ainda não andam e não falam?

Este artigo tem o propósito de trazer contribuições para a formação de professores(as) de Educação Infantil. O curso de Pedagogia, de um modo geral, não tem cumprido com essa tarefa; os estudantes, futuros professores(as), sentem-se despreparados para atuar com as crianças pequenas; os conhecimentos sobre esta etapa da educação são incipientes nos cursos e os próprios professores(as) dos cursos de formação não demonstram uma compreensão ampla e consistente sobre o trabalho docente com as crianças pequenas.

A docência na Educação Infantil constitui-se em um campo em construção (BARBOSA, 2016; ROCHA, 1999) com características peculiares, que difere do modelo de professor(a) da escola. Na educação das crianças pequenas são as relações entre os sujeitos: adulto-adulto, adulto-criança e criança-criança que conferem sentido à existência das instituições educativas. Ser professor(a) de creche ou de pré-escola não é o 
mesmo que ser professor(a) de disciplina escolar que ensina conteúdos - é outra profissão, uma profissão que está sendo inventada (MANTOVANI; PERANI, 1999), juntamente com as concepções contemporâneas de criança, infância e Educação Infantil.

Atualmente o curso de pedagogia forma professores(as) para atuar na Educação Infantil e nos anos iniciais do Ensino Fundamental; mas não basta assumir a docência como foco do curso, é preciso ter a clareza que se trata da formação professores(as) de crianças. Os conhecimentos difundidos no curso de pedagogia mostram-se distantes dos saberes e fazeres que envolvem o cuidar e o educar de crianças pequenas.

O texto destaca as especificidades da docência na Educação Infantil e, portanto, na formação de professores(as) para atuar com as crianças pequenas. Inicialmente, apresenta uma discussão sobre a docência na Educação Infantil e a formação no curso de pedagogia. Busca analisar as contribuições dos estágios na construção de saberes, enquanto espaço da pesquisa e da inovação pedagógica. E, por fim, questiona as bases epistemológicas do curso de pedagogia ao propor a arte como um de seus fundamentos, uma vez que essa atividade traz contribuições para a formação e a docência com as crianças pequenas.

\section{A Educação Infantil e a Pedagogia}

Os estudos que discutema formação de professores(as) têm se constituído em foco de atenção; entretanto, as políticas e as pesquisas educacionaisnão têm privilegiado o trabalho docente na Educação Infantil. Os sconhecimentos sobre a educação da criança pequena ocupam um espaço restrito e limitado nos currículos dos cursos de pedagogia e, além disso, os conhecimentos difundidos sobre a educação das crianças pequenas não contemplam os saberes e fazeres que caracterizam a docência com crianças dessa faixa etária.

A pesquisa desenvolvida por Gatti e Barreto (2009) analisou cursos de pedagogia que formam docentes para atuar na primeira etapa da Educação Básica e nos anos iniciais do Ensino Fundamental, conjuntamente, como recomendado pelas Diretrizes Curriculares Nacionais para o Curso de Pedagogia DCNP (BRASIL, 2006). Esse estudo envolveu cursos de Pedagogia de 71 instituições, entre Faculdades particulares, Universidades Estaduais e Federais de diversas regiões do País. Destaca-se o baixo percentual de atenção curricular à Educação Infantil (5,3\%).

A pesquisa citada, entre outras, mostra que as discussões voltadas para a Educação Infantil são ainda periféricas na maioria dos cursos de pedagogia e na formação de professores(as) para a Educação Básica. O curso de pedagogia deve formar docentes para atuar na primeira etapa da Educação Básica, a Educação Infantil, e na primeira fase do Ensino Fundamental, do $1^{\circ}$ ao $5^{\circ}$ ano. Assim, as universidades têm que assumir o compromisso de repensar os seus projetos curriculares, propor cursos que formem professores(as) de crianças de 0 a 6 anos e de 6 a 10 anos, com a especificidade da creche, da pré-escola e dos anos iniciais do Ensino Fundamental.

Rocha (1999) analisou a produção de pesquisas em Educação Infantil no Brasil, a partir dos trabalhos apresentados em congressos científicos da área. Mostra que, ao final dos anos de 1990, identifica-se a acumulação de conhecimentos sobre a educação da criança pequena, com origem em diferentes campos 
científicos, que tem resultado em contribuições para a constituição de um campo particular no âmbito da pedagogia, denominado pela autora de "Pedagogia da Educação Infantil". Começou a difundir-se no discurso pedagógico a necessidade de construir uma pedagogia para a Educação Infantil, que vem sendo considerada como um campo de conhecimento em construção.

Este conjunto de relações que poderia ser identificado como o objeto de estudo de uma "didática" da educação infantil, é que, num âmbito mais geral, estou preferindo denominar de Pedagogia da Educação Infantil ou até mesmo, mais amplamente falando, uma pedagogia da Infância, que terá, pois, como objeto de preocupação a própria criança (ROCHA, 2001, p. 31, grifo da autora).

Desse modo, Rocha (1999) considera a importância da construção de uma Pedagogia da Educação Infantil que considere as especificidades das crianças pequenas e propõe, em termos mais amplos, a necessidade de uma Pedagogia da Infância que contemple a docência com crianças de 0 a 10 anos; ou seja, da Educação Infantil e dos anos iniciais do Ensino Fundamental.

A pesquisa na área da Educação Infantil vem aumentando e se sofisticando nas últimas décadas, trazendo outras abordagens para discutir a pequena infância. Faria (2005) destaca outras categorias de análise a serem observadas na pesquisa com crianças pequenas:

[...] tempo, espaço, relações, gênero, classes sociais, arranjos familiares, transgressão, culturas infantis, brincar, documentação, identidades, planejamento por projeto, performance, diferente, outro, linguagens, movimento, gesto, criança, alteridade, turma, instalação, não-avaliação, observação, cuidado. Isso, em vez dos convencionais: deficiência, indisciplina, hiperativo, carente, família desestruturada, anamnese, rotina, assistência, aula, didática, classe, aluno, ensino, currículo, vir-a-ser, sala de aula, desenvolvimento (FARIA, 2005, p. 1.018).

A questão da formação inicial de professores(as) de crianças pequenas ganha importância, na medida em que a instituição de Educação Infantil possui características diferentes da escola do Ensino Fundamental e tem uma proposta de educação diferenciada. Portanto, requer, do(a) profissional docente, saberes que contemplem as especificidades das crianças pequenas. Nesse sentido, Rocha (1999, p. 62) aponta que,

Enquanto a escola se coloca como espaço privilegiado para o domínio dos conhecimentos básicos, as instituições de educação infantil se põem, sobretudo, com fins de complementaridade à educação da família. Portanto, enquanto a escola tem como sujeito o aluno e como o objeto fundamental o ensino nas diferentes áreas através da aula; a creche e a pré-escola têm como objeto as relações educativas travadas no espaço de convívio coletivo, que tem como sujeito a criança de 0 a 6 anos de idade (ou até o momento que entra na escola).

Freitas (2007) destaca as particularidades da Educação Infantil, que representa um universo com forma própria, dentro do qual está a "forma-creche", com uma formatação diferente daquela comumente difundida do espaço escolar, justamente porque tem uma maneira peculiar de constituir-se. Portanto,

é na singularidade da construção quotidiana do espaço, do tempo, da organização e das práticas, que o trabalho com a criança pequena ganha uma tonalidade própria. [...] é fundamental ter em conta que o específico da educação infantil não deve ser reconhecido no "reino da prática". Ou seja, o peculiar da educação de crianças pequenas não é o mister das mãos, tão pouco é o triunfo da prática sobre a teoria. [...] Mas se não é o imperativo da prática aquilo que singulariza o trabalho com crianças pequenas, o que do seu conteúdo é "estritamente seu" a ponto de fazer com que espaço, tempo, organização e práticas escapem da poderosa forma escolar? $\mathrm{O}$ que lhe é essencialmente particular é a própria "cultura da infância" (FREITAS, 2007, p. 10-11, grifos do autor). 
Para esse autor, o coletivo infantil é a expressão de uma universalidade que só se torna efetivamente compreensível de perto e representa "um microcosmo a ser desvelado" (FREITAS, 2007, p. 12). Por isso mesmo, os(as) pesquisadores(as) de crianças pequenas vêm recorrendo às etnografias, aos estudos descritivos das relações entre as crianças nos coletivos infantis, com o objetivo de analisar a produção das culturas infantis. As pesquisas com crianças pequenas têm desvelado um mundo infantil que, por muito tempo, passou despercebido ou foi negligenciado nos estudos educacionais.

O direito à Educação Infantil exige profissionais formados(as), comprometidos(as) com o conhecimento, com um projeto de educação com conteúdo; porém, não escolar, centrada na criança. Para tal empreitada, o(a) professor(a) da primeira etapa da Educação Básica não ministraaulas, não é professor(a) de disciplinas escolares de uma grade curricular, mas é um(a) professor(a) de criança com intencionalidade educativa.

Tal qual uma cenógrafa, a professora (des)organiza o espaço e o tempo do capital frequentemente reproduzidos nas instituições educativas desde a primeiríssima infância. Sem a aula e sem o conteúdo escolar, à docência nas creches e pré-escolas organiza outra forma, outra pedagogia (diferente do ensino fundamental) adequada aos conteúdos das práticas culturais e dos saberes oriundos dos movimentos sociais engajados na transformação social, atenta às experiências infantis, às especificidades etárias encontradas no coletivo. Trata-se de uma profissão que está sendo inventada: a docente de crianças de 0 a 6 anos em espaços coletivos de educação e cuidado. (FARIA, 2011, p. 14).

O curso de Pedagogia forma os(as) estudantes para três tipos de docência: a docência para a creche, para a pré-escola e para os anos iniciais do Ensino Fundamental. Cabe, então, visando a uma Pedagogia da Infância, uma formação docente que não antagonize a cultura lúdica e as culturas da escrita, que forneça os instrumentos para as docentes reverem suas práticas e as relações de dominação com as crianças (FARIA, 2011).

Bufalo (2009) emprega a palavra "docente" para as profissionais que atuam diretamente com as crianças nas creches, partindo do pressuposto de que elas não têm o atributo do exercício do magistério para "dar aulas". Têm, sim, outras peculiaridades compondo essa docência, as quais partem da concepção de crianças como seres culturais, sociais e políticos; portanto, essas docentes são concebidas como construtoras de culturas infantis.

$\mathrm{Na}$ docência da Educação Infantil, a centralidade não está nos(as) professores(as): as crianças é que são o centro. Esse contexto já traz um condicionante para uma pedagogia diferenciada de outras áreas da educação. Para tanto, os(as) docentes organizam espaços e tempos para que as crianças vivam suas infâncias. Seria possível definir essas docências como uma pedagogia das relações e/ou das escutas, como muito bem demonstra Russo (2007, p. 67):

$\mathrm{Na}$ relação comigo, os meninos e as meninas podem aprender a usar um dado material, aprender o uso correto de certas palavras, a conectar lembranças e a contá-las, a ter contato com os livros, etc. Mas a relação que têm comigo - como elas a veem - é, ela própria, alguma coisa que eles aprendem: o conteúdo desta aprendizagem particular é uma forma.

A docência na Educação Infantil é diferente da docência na escola de Ensino Fundamental e isso precisa ser explicitado para que as especificidades do trabalho docente com as crianças pequenas, em creches 
e pré-escolas, sejam respeitadas e garantidas. A docência na Educação Infantil tem características peculiares que o conhecimento produzido acerca da escola não dá conta de explicar.

Barbosa (2016) no texto: "Três notas sobre a formação inicial e a docência na Educação Infantil”, afirma que a formaçãoprecisa partir da experiência e de um olhar aprofundado sobre a infância e a Educação Infantil e que a docência na Educação Infantil é uma atividade profissional que implica a pesquisa e a militância. Além disso, reforça a ideia de que a docência na Educação Infantil não é convencional: está em processo de invenção. Como ressalta a autora,

Estamos, neste momento histórico mapeando o que configura esta "peculiar" docência. Uma docência que se caracteriza por ser indireta, por ser relacional, por não ministrar aulas por não estar centrada em conteúdo, por estar com as crianças e não controlando-as, isto é, por desconstruir aquilo que foi identificado como o cerne, o óbvio da docência. (BARBOSA, 2016, p. 132).

É fundamental reconhecer que o curso de pedagogia tem falhado na formação de professores(as) de Educação Infantil. "As crianças de 0 a 3 anos estão invisíveis nos currículos, as disciplinas metodológicas centram-se em áreas de conhecimento acadêmicas nem sempre pertinentes à creche"(BARBOSA, 2016, p. 133). Para Barbosa (2016) a formação do "dois em um", curso de pedagogia e o curso normal e ou magistério, condensado em quatro anos, talvez não seja exatamente a opção adequada para a formação de profissionais docentes, licenciados; isto é, professores que atuam junto às crianças.

As pesquisas na área da Educação Infantil apontam a necessidade de uma pedagogia que forme professores(as) para atuar com crianças pequenas, que considere os saberes próprios dessa etapa educacional. Portanto, discutir a formação docente para a Educação Infantil implica problematizar os cursos de formação inicial de professores(as) de crianças pequenas e analisar os saberes que têm sido produzidos nestes cursos, nas disciplinas curriculares e nos estágios.

\section{Educação Infantil: Estágio, Pesquisa e Inovação}

A partir das novas Diretrizes curriculares nacionais do curso de Pedagogia (BRASIL, 2006), a formação de professores(as) de Educação Infantil passou a ser contemplada nos cursos universitários, com a obrigatoriedade do estágio docente em creches e pré-escolas. Assim, os cursos de pedagogia viram-se diante do desafio de reformular seus projetos curriculares e propor cursos que formem os(as) estudantes para três tipos de docência: a docência para a creche, para a pré-escola e para os anos iniciais do Ensino Fundamental.

Nesse cenário, os cursos de Pedagogia passaram a discutir a docência e o estágio curricular nos anos iniciais do Ensino Fundamental e também na Educação Infantil. E isso significa dotar o conteúdo das disciplinas que integram o curso de conhecimentos específicos sobre as crianças pequenas em espaços coletivos de educação e cuidado como as creches e as pré-escolas.

O estágio representa um momento privilegiado na formação inicial de docentes, pois favorece o contato direto com o futuro campo de trabalho. É o espaço da experiência e da vivência, é quando o estudante busca, a partir do contato com as instituições de Educação Infantil, entender aquele contexto. Além disso, o estágio favorece a pesquisa, pois promove a reflexão e a formação. Portanto, discutir e problematizar 
os estágios nas creches e nas pré-escolas pode trazer contribuições para a formação de professores(as) de Educação Infantil.

Tenho observado, durante os estágios nas instituições de Educação Infantil, que os(as) professores(as) com formação voltada para a escola de Ensino Fundamental acabam usando esses mesmos conhecimentos na educação das crianças pequenas, por receio de não saber fazer diferente do que aprenderam. Para construir com os(as) estudantes-estagiários(as) referências teóricas e metodológicas para a docência na Educação Infantil, os estágios em creches e pré-escolas tomam os três protagonistas da Educação Infantil: as crianças, os(as) professores(as) e as famílias (SPAGGIARI, 1998), tendo a criança como protagonista privilegiada, como referência na construção de saberes na formação de docentes. O estágio na Educação Infantil deve considerar as diversas relações presentes no cotidiano das instituições e não unicamente a relação entre o(a) professor(a) e as crianças (DRUMOND, 2014).

Desse modo, os(as) estagiários(as) analisam a relação entre os(as) profissionais docentes que trabalham nas instituições e as famílias; a relação entre os(as) profissionais que atuam nas creches e nas préescolas, problematizando a formação docente; a relação entre adultos e crianças a partir das políticas públicas; a relação entre professores(as) e as crianças; as relações entre as crianças e a produção das culturas infantis.

Embora os textos acadêmicos e também alguns documentos oficiais digam que o trabalho pedagógico na Educação Infantil envolve o cuidar e o educar de maneira indissociável, é no momento dos estágios, no contato com o cotidiano de professores(as) e crianças, que os(as) estudantes de pedagogia se dão conta do que significam tais conceitos. Especialmente, no que diz respeito à creche; ou seja, ao cuidar e ao educar de criança de 0 a 3 anos, em que a organização do tempo e do espaço é diferente da estrutura da escola.

O contato, durante os estágios, com a prática educativa em creches e pré-escolas, com o cotidiano de professores(as) e crianças que frequentam estas instituições possibilitou discutir temas relacionados à docência envolvendo crianças pequenas. Conhecimentos que, na maioria das vezes, não são abordados no curso de pedagogia, pois este, de modo geral, valoriza a cognição e a aprendizagem de conteúdos, em detrimento do movimento, do corpo, das brincadeiras, da ludicidade, das invenções, que são próprios das crianças.

Desse modo, desde as primeiras experiências com os estágios na Educação Infantil, percebi a necessidade de registrar os aspectos que foram observados durante as idas às creches e às pré-escolas, pela novidade que se apresentava aos(às) estudantes. Eles(as) foram orientados a construir um registro descritivo (caderno de campo/estágio), destacando o que foi observado: o espaço físico; as relações entre os adultos, entre os adultos e as crianças, entre as crianças; a rotina; as atividades propostas pelas professoras; as manifestações das crianças etc., além de registrar as conversas informais ou as entrevistas com profissionais da equipe gestora e com as professoras, leitura de documentos, planejamento e cadernos de planejamento e registros das professoras. Foi a partir desse movimento de orientação e acompanhamento dos(as) estagiários(as) nas creches e nas pré-escolas que comecei a refletir sobre a metodologia dos estágios na 
Educação Infantil, buscando compreender de que forma esta se aproxima e se distancia das questões que envolvem os estágios no Ensino Fundamental.

Além disso, o trabalho com os estágios na Educação Infantil mostrou a necessidade de construir referências para fundamentar a docência com as crianças pequenas. Os conhecimentos da didática e das metodologias de ensino, que geralmente subsidiam a disciplina de estágio, no planejamento de aulas e na elaboração de projetos de ensino, no caso da Educação Infantil, são ferramentas que se mostraram inadequadas. Uma vez que o(a) professor(a) de Educação Infantil não "dá aulas", não é um professor de disciplinas escolares mas, sim, um(a) professor(a) de crianças que organiza o tempo e o espaço da Educação Infantil.

No artigo "Uma profissão a ser inventada: o educador da primeira infância", Mantovani e Perani (1999) descrevem a experiência - realizada na Itália - de formação de professores(as) de Educação Infantil para atuar nas creches implantadas após a reforma legislativa nos anos de 1970. Para as autoras, a creche de "novo tipo" exigiu desde o início a formação de "novos educadores"; ou seja, o problema da formação de professores(as) foi enfrentado juntamente com a implantação das creches e não transferido para períodos posteriores ou para outras instâncias. As próprias prefeituras, responsáveis diretas pelas creches, assumiram a tarefa de formar seus(suas) professores(as), pois partia-se da ideia de que a formação era uma das questões centrais na construção do projeto em andamento.

Assim, juntamente com a proposta das creches com caráter educativo e não mais assistencialista, foram pensados o papel e a formação de professores(as). A profissão de professores(as) de creche estava sendo inventada e, considerando sua complexidade, foram precisos novos instrumentos para produzir as necessárias modificações de atitude e de comportamento dos(as) professores(as) (MANTOVANI; PERANI, 1999).

O educador Loris Malaguzzi (apud FARIA, 2007) dizia que, para uma criança diferente, é preciso uma escola diferente e também uma professora diferente. Mas essa professora não existia, precisou ser inventada a cada dia, trabalhando junto com as crianças e com os outros adultos, experimentando, errando, corrigindo, revendo e refletindo sobre o trabalho realizado. Nesse processo, estar junto com as crianças e manter o distanciamento necessário para observá-las tornou-se uma das ferramentas mais importantes para a prática pedagógica.

Portanto, discutir uma "nova" formação significa que os conteúdos dessa formação devem ser revistos, de modo a garantir aos(às) futuros(as) profissionais a aquisição de referências para atuar na docência com crianças pequenas e isso impõe a definição de novos currículos de formação, que contemplem, além dos conhecimentos teóricos e da pesquisa empírica, as informações em contexto real, a observação nas creches e nas pré-escolas. Nesse sentido, para Mantovani e Perani (1999), a formação prática por meio de estágio, por um período de tempo prolongado, revelou-se uma experiência extremamente significativa na formação de professores(as) de crianças pequenas. O estágio foi entendido e cada vez mais reconhecido como momento central da formação de professores(as) de crianças pequenas. 
Assim, o estágio de Educação Infantil mostrou ser um campo fértil para investigar a relação teoriaprática e as diferentes concepções epistêmicas e pedagógicas das estudantes-estagiárias de Pedagogia e, sobretudo, reafirmar a importância do estágio na formação de professores(as) de Educação Infantil. Os dados dos estágios realizados nas creches e nas pré-escolas permitiram construir reflexões sobre o cotidiano das crianças e dos adultos nestes espaços, mostrando a importância da construção de uma Pedagogia da Educação Infantil.

\section{A Contribuição da Arte na Formação de Docentes de Educação Infantil}

A pedagogia é reconhecida como a ciência da educação; porém, nos livros clássicos de pedagogia há uma tendência a considerá-la também como arte (FRANCO, 2008). Desse modo, muitas vezes a pedagogia é conceituada como a ciência e a arte da educação, ou mesmo a ciência da arte educativa. A pedagogia, "mesmo sendo ciência têm em comum com a arte, a atividade prática, fabricadora, não se restringindo à teoria, mas também formulando regras diretivas da obra educativa" (Anísio, 1934 apud FRANCO, 2008, p. 27).

O filósofo Johann Herbart, considerado o criador da pedagogia científica (FRANCO, 2008; CAMBI, 1999) propõe uma cientificidade que qualifique a "arte pedagógica". Sua proposta inicial não busca separar ciência e arte da educação, mas sim propor uma ciência que se organize para compreender e qualificar a imanência do artístico na realização da prática educativa. $\mathrm{O}$ autor considera a pedagogia como ciência filosófica que tem como objetivo o "governo das crianças" e mantinha a convicção de ser a pedagogia uma ciência filosófica que deveria conjugar teoria e prática, arte e ciência.

Mas, na busca por cientificidade e racionalidade na definição do campo de estudo da pedagogia, ela foi compreendida como uma ciência ou tecnologia educacional. Assim, "o fazer pedagógico vai perdendo o sentido de criação, vai se limitando, empobrecendo, mudando o perfil dos professores, que de criadores da prática, passam a ser aplicadores de descobertas de outrem" (FRANCO, 2008, p. 29).

Assim, a pedagogia, como ciência da educação, envolve as dimensões da técnica e da arte. Portanto, a pedagogia compreende a ciência, a técnica e a arte. A arte nos oferece fundamentos para compreender as crianças e, também, para subsidiar teórica e metodologicamente o trabalho docente junto às crianças.

[...] a docência na Educação Infantil exige integrar a ciência, a arte e a técnica, superando o tecnicismo pedagógico e cientificismo sem cair no praticismo. Exige resgatar suas bases filosóficas e estéticas [...] cuja intenção não é discorrer sobre arte e infância, mas entre elas firmar uma cumplicidade de mútuos aprendizados, Com elas re-aprender o pacto poético de fazer nascimentos: com elas recuperar o delírio dos recomeços na aventura humana de afrontar o desconhecido e o incerto. Trata-se de construir uma pedagogia da infância para o coletivo infantil desde as crianças pequenininhas, partindo dessas características humanas aí projetadas. Uma pedagogia enquanto ciência da prática impõe um esforço interdisciplinar, superando a fragmentação do pensamento, articulando permanentemente teoria e prática(FARIA; RICHTER, 2009, p. 106).

$\mathrm{O}(\mathrm{A})$ professor(a) que atua com as crianças pequenas deve ter formação em arte, para trabalhar com as "cem linguagens das crianças"2. Com efeito, as pesquisadoras Albano (2007, 2008), Faria e Richter (2009), Gobbi (2007) e Holm (2004), que discutem a relação entre a arte e as crianças, destacam a contribuição da

\footnotetext{
2 Poema "Ao contrário, as cem existem" de Loris Malaguzzi.
} 
arte, tanto para o trabalho de professores(as) de Educação Infantil, no dia a dia com as crianças, quanto para a formação daqueles(as) que são ou serão professores(as) de crianças. Mas esse é um assunto ainda pouco discutido nos cursos de pedagogia. Para Faria e Richter (2009), a arte deveria ser um dos fundamentos epistemológicos da Pedagogia, ao lado das outras ciências, pois,

[..] se as crianças são inventivas, também se faz necessária uma formação profissional sofisticada, inventiva, de outro tipo que permitirá que as professoras, com a filosofia, a história e as ciências (psicologia, sociologia, antropologia, demografia etc.) e a ARTE como fundamentos desta formação, "soltem sua dimensão brincalhona" e construam esta nova profissão: a professora de crianças de 0 a 6 anos em creches e pré-escolas, isto é, da educação infantil, primeira etapa da educação básica. [...] A arte como fundamento ao lado das ciências também com certeza trará repertório inovador para uma pedagogia de processo (e não de resultado), como se espera de uma pedagogia de 0-10 anos (FARIA, 2011, p. 15).

No seu trabalho com a disciplina Prática de Ensino de Arte a professora Angélica Albano (2008) procurou desenvolver uma proposta na qual a prática artística dialogasse com a leitura de textos teóricos e literários, imagens e poemas. Observou que a inclusão de textos poéticos entre as leituras obrigatórias revelou-se produtiva e veio confirmar a tese de que os artistas e os poetas são interlocutores privilegiados para quem trabalha com a primeira infância, pois recuperam para a educação aquilo que a criança ainda não perdeu: a capacidade de imaginar. Assim, as crianças se aproximam dos artistas e vice-versa.

Albano (2008, p. 23) considera que os(as) professores(as) dão pouca atenção à própria educação estética e simplesmente aceitam que o desenho seja algo que se perdeu com o tempo ou algo reservado a quem possui um dom especial. Entretanto, a partir de sua experiência no trabalho com a arte na formação de professores(as), diz: “[...] o primeiro passo é levá-los(as) a perceber que a arte é uma linguagem, uma forma de comunicação que transmite o que as palavras não conseguem". As(Os) professoras(es) comentam que, na sua formação anterior, tiveram poucas oportunidades de experimentar as suas ideias numa linguagem visual. Chegam à conclusão de que é necessária uma grande variedade de experiências, com diferentes materiais e técnicas, pois como vão valorizar as experiências das crianças, se eles mesmos não tiveram uma formação voltada para a arte?

Gobbi (2007) traz elementos para propor a arte como um dos fundamentos na formação docente, ao lado das ciências e da filosofia, pois a Educação Infantil encontra, na arte, subsídios para a construção de uma pedagogia que valorize as múltiplas formas de expressão e as linguagens infantis, de modo que o ingresso das crianças nas culturas da escrita não se antagonize com as culturas lúdicas; as crianças são expressivas, e a escrita não é a única, mas uma das linguagens infantis.

A educação escolar, geralmente, separa a cabeça do corpo, o sentir do pensar, o saber do fazer, minando a capacidade de inventar, criar e imaginar, própria da criança. Ao trazer os artistas para o diálogo, Gobbi (2007, p. 30) propõe que "a infância possa ser concebida como uma etapa da vida na qual as crianças são vistas como seres falantes, criativos, e isto, sobretudo, quando ainda estão livres das tradicionais tutelas sociais, tais como os padrões escolares, restritivos da imaginação e da criatividade".

Sobre a importância da arte na formação do(a) professor(a) de Educação Infantil, Faria e Richter (2009, p. 104) afirmam que: 
o que o encontro entre arte e infância tem mostrado são as lacunas na formação do pedagogo(a) que convive e trabalha com crianças pequenas, principalmente com as pequenininhas, para educá-las muito além do cognitivismo reinante. O destaque aqui dado à imaginação poética, à alegria e à complexidade de aprender, ao direito à beleza, à comunicação não verbal, enfim, à arte como experiência de um corpo em suas primeiras aprendizagens, evoca uma pedagogia que não separa experiência e saber, corpo e mente, pensamento e ação no mundo. Problematizando as bases exclusivamente científicas da Pedagogia e seu tecnicismo estrutural - a didática - estamos tentando com a arte preencher as lacunas da formação docente, rumo a uma pedagogia da infância. Assim apostamos que outra pedagogia é possível.

Na Educação Infantil, o centro é a criança, e não o(a) professor(a); o foco de atenção é o processo e não o resultado, pois se trata de uma educação que tem suas bases nas experiências das crianças. E o(a) professor(a) da Educação Infantil é um(uma) professor(a) de crianças, o que é diferente de ser professor(a) da escola que ensina conteúdos escolares. Mas, com isso, não quero desqualificar o trabalho do(a) docente com crianças pequenas e, sim, o contrário, pois é afirmando as diferenças e considerando as especificidades dessa profissão que ela será reconhecida e valorizada.

Nesse sentido é que o resgate da arte como um dos fundamentos da educação, ao lado das outras ciências, pode trazer referências para construir uma Pedagogia da Infância que, evitando práticas adultocêntricas ${ }^{3}$, compreenda a criança como produtora de culturas infantis, como um ser capaz, desde bem pequena.

A ciência, tendo a seu lado a técnica, não tem oferecido referências para uma pedagogia que perceba, que ouça e valorize as crianças e suas culturas. A arte como um dos fundamentos na formação de professores(as) de Educação Infantil, mostra perspectivas para o trabalho pedagógico e educativo com as crianças pequenas.

Os conhecimentos produzidos no âmbito da Pedagogia da Educação Infantil buscam mostrar as lacunas presentes na formação de docentes de crianças pequenas e indicam outras referências para discutir a docência nessa etapa educacional, que deve estar centrada na experiência da criança, no processo e não no produto ou no resultado. A arte pode trazer novos significados para a construção de pedagogias que formem professores(as) de crianças.

\section{Considerações Finais}

A pedagogia é uma ciência social aplicada; portanto, uma ciência da prática, que busca suas bases epistemológicas em outras ciências, como a sociologia, a psicologia, a filosofia e outras. A ausência de um campo epistemológico próprio na pedagogia não significa carência de referências teóricas; ao contrário, a relação entre teoria e prática está implícita na pedagogia, como ciência da prática (FREITAS, 1994). Portanto, a pedagogia é uma ciência da prática, que tem suas bases epistemológicas nas ciências da educação e na arte, como as outras ciências da prática: a medicina, a engenharia, a enfermagem entre outras.

${ }^{3}$ Conceito usado por Fúlvia Rosemberg no texto: Educação para quem? Revista Ciência e Cultura. São Paulo, v. 28, n. 12, p. 1.4661.471, dez. 1976. 
Então, cabe fazer uma crítica radical da matriz formativa que temos para a escola de hoje, que é a matriz cognitiva. E isso afeta fundamentalmente e dramaticamente a Educação Infantil. Portanto, o alargamento da matriz formativa mostra-se como uma exigência da própria base da formação do(a) professor(a). Se quisermos uma educação em que o(a) professor(a) trabalhe com as várias dimensões da formação humana, que não se restrinja somente ao cognitivo, isso implica em alargar a matriz formativa para dar conta de formar um ser humano que é, além de cognitivo, afetivo, criativo; que inventa; que tem um corpo; que é plural. Então, falo de uma formação mais ampla do que aquela que se resume a um treinamento para garantir a aprendizagem da leitura e da escrita; falo de uma educação que respeite as crianças e suas formas de expressão e de pensamento.

As teorias pedagógicas, apoiadas nas reflexões filosóficas, foram construídas por um repertório de ideias em oposição e contraditórias, que preconizam práticas que envolvem maior ou menor grau de liberdade ou de autoritarismo. As diferentes concepções sobre as aprendizagens humanas orientaram a construção de propostas educacionais marcadas por discursos pedagógicos antagônicos, estabeleceram oposições entre natureza e cultura, corpo e mente, o intelectual e o manual, passividade e atividade, a teoria e a prática, o sujeito e o objeto, entre outros.

Uma proposta de educação emancipatória e descolonizadora para a primeira infância exige a ação de profissionais docentes compromissados com uma pedagogia não escolar, centrada na criança e na experiência infantil, que proporcione a construção de todas as dimensões humanas, geralmente negadas na escola regular: o imaginário, o lúdico, o artístico. As crianças não separam saber e experiências; assim, espera-se que elas possam brincar, descobrir, inventar, criar; e produzir as culturas infantis.

A articulação entre educação e cuidado, saber e experiência, teoria e prática, numa perspectiva dialética, permite afirmar as especificidades da Educação Infantil, que precisam ser resguardadas, para não se perder em meio ao turbilhão de propostas que procuram antecipar a escolarização, transformando as crianças em pequenos alunos, com processos avaliativos excludentes. Afirmar o específico e singular da Educação Infantil não significa defender uma educação de segunda categoria ou de menor valor; ao contrário, representa o reconhecimento e a valorização dessa área de conhecimento, do respeito aos direitos das crianças e dos(as) profissionais docentes que trabalham com elas.

Neste sentido, cabe aos Cursos de Pedagogia reverem seus projetos pedagógicos curriculares, de modo a construir percursos formativos, que atenda às necessidade dos(as) professores(as) de criança de 0 a 5 anos e de 6 a 10 anos. Que a matriz formativa com ênfase no cognitivo seja revista com espaço para os saberes de outros campos de conhecimento, que contemple a complexidade que envolve a formação do ser humano integral; que a arte seja um dos fundamentos ao lado das outras ciências na formação de professores(as) de crianças.

Desse modo, este estudo destaca a importância da construção de uma Pedagogia que forme docentes para atuar nas creches, nas pré-escolas e nos anos iniciais do Ensino Fundamental; ou seja, um curso de formação de professores(as) de crianças; portanto, uma Pedagogia da Infância. 


\section{Referências}

ALBANO, Ana Angélica. Transformar a realidade. Infância na Europa, Portugal, v. 14, p. 23-24, 2008.

ALBANO, Ana Angélica. Prefácio: Com olhos de criança. In: HOLM, Anna Marie. Baby-Art: os primeiros passos com a arte. São Paulo: Museu de Arte Moderna de São Paulo, MAM, 2007. p. 7-8.

BRASIL. Lei Federal no 9394/96/LDB. Estabelece as diretrizes e bases da Educação Nacional. Diário Oficial da União, Brasília, DF, 23 de dezembro de 1996.

BRASIL.Ministério da Educação. Conselho Nacional de Educação. Resolução CNE/CP nº 1, de 15 de maio de 2006. Institui Diretrizes Curriculares Nacionais para o Curso de Graduação em Pedagogia, licenciatura. Brasília: MEC/CNE, 2006.

BARBOSA, Maria Carmem Silveira. Três notas sobre formação inicial e docência na educação infantil. In. CANCIAN, Viviane Ache; GALLINA, Simone Freitas da Silva, WESCHENFELDE. Noeli (Orgs.). Pedagogias das infâncias, crianças e docências na educação infantil. Brasilia: Ministério da Educação, Secretaria da Educação Básica, 2016.

BUfALO, Joseane Maria P. Nem só de salários vivem as docentes de creche: em foco as lutas do sindicato dos trabalhadores no serviço público municipal de Campinas (STMC 1988-2001). 179 f.Tese (Doutorado) - Faculdade de Educação, UNICAMP, Campinas, 2009.

CAMBI, Franco. História da pedagogia. São Paulo: Editora da Unesp, 1999.

DRUMOND, Viviane. Formação de professores e professoras de educação infantil no curso de pedagogia: estágio e pesquisa. 236f. Tese (Doutorado) - Universidade Estadual de Campinas, Faculdade de Educação, 2014.

FARIA, Ana Lúcia Goulart de. Loris Malaguzzi e os direitos das crianças pequenas. In: OLIVEIRAFORMOSINHO, Júlia; KISCHIMOTO, Tizuko Morchida; PINAZA, Mônica Appezzato. Pedagogia(s) da Infância: dialogando com o passado, construindo o futuro. Porto Alegre: Artmed, 2007. p. 277-292.

FARIA, Ana Lúcia Goulart de. Políticas de regulação, pesquisa e pedagogia na educação infantil, primeira etapa da educação básica. Educação e Sociedade, Campinas. v. 26, n. 92, p. 1.013-1.038, out. 2005.

FARIA, Ana Lúcia Goulart de. Apresentação. In: GEPEDISC - Culturas Infantis (Org.) Culturas infantis em creches e pré-escolas: estágio e pesquisa. Campinas, SP: Autores Associados, 2011, p. 13-17.

FARIA, Ana Lúcia Goulart de; RICHTER, Sandra Regina Simonis. Apontamentos pedagógicos sobre o papel da arte na educação da pequena infância: como a pedagogia da educação infantil encontra-se com a 
arte? In: SMALL SIZE PAPER (Org.) Experiencing art in early years - learning and development processes and artistic language. Bologna: Edizioni Pendragon, 2009. p. 103-25.

FRANCO, Maria Amélia Santoro. Pedagogia como ciência da educação. São Paulo: Cortez, 2008.

FREITAS, Luiz Carlos de. Crítica da organização do trabalho pedagógico e da didática. $305 \mathrm{f}$. Tese (Livre-Docência) - Faculdade de Educação, Unicamp, Campinas, SP, 1994.

FREITAS, Marcos Cezar. Prefácio: O coletivo infantil: o sentido da forma. In: FARIA, Ana Lúcia Goulart de (Org.). O coletivo infantil em creches e pré-escolas: falares e saberes.São Paulo: Cortez, 2007. p. 7-13.

GATTI, Bernadete A.; BARRETO, Elba Siqueira de Sá (Coord.) Professores do Brasil: impasses e desafios. Brasília: UNESCO, 2009.

GOBBI, Marcia. O fascínio indiscreto: crianças pequenininhas e a criação de desenhos. In: FARIA, Ana Lúcia Goulart de; MELLO, Suely Amaral (Org.). Territórios da infância: linguagens, tempos e relações para uma pedagogia para as crianças pequenas. Araraquara, SP: Junqueira e Marin, 2007. p. 119-136.

GOBBI, Marcia; RICHTER, Sandra. Apresentação - Interlocução possível: arte e ciência na educação da primeira infância. Pro-Posições, Campinas, v. 22, n. 2 (65), p. 15-20, maio/ago. 2011.

HOLM, Anna Marie. A energia criativa natural. Pro-Posições. v. 15, n. 1 (43), p. 83-95, jan./abr. 2004.

MANTOVANI, Susanna; PERANI, Rita. Uma profissão a ser inventada: o educador da primeira infância.

Pro-Posições,Campinas, v. 10, n. 1 (28), p. 75-98, mar. 1999.

ROCHA, Eloísa Acires Candal. A Pedagogia e a Educação Infantil. Revista Brasileira de Educação Anped, São Paulo, n. 16, p. 27-34, jan./abr. 2001.

ROCHA, Eloísa Acires Candal. A Pesquisa em Educação Infantil no Brasil: trajetória recente e perspectiva de uma consolidação de uma Pedagogia. 262 f. Tese (Doutorado em Educação)-Faculdade de Educação, Universidade Estadual de Campinas: UNICAMP, 1999.

RUSSO, Danilo. De como ser professor sem dar aulas na escola da infância. In: FARIA, Ana Lúcia G. (Org.) O coletivo infantil em creches e pré-escolas: falares e saberes. São Paulo: Cortez, 2007. p. 67-93.

SPAGGIARI, Sergio. Considerações críticas e experiências de gestão social. In: BONDIOLI, Anna; MANTOVANI, Susanna. Manual de educação infantil de 0 a 3 anos. 9. ed. Porto Alegre: Artes Médica 